\title{
Effect of fiber orientation on the mechanical properties of natural fiber epoxy reinforced composites of Flax, Hemp, and Kenaf
}

\author{
Rapeta Sundara Ramam $^{1^{*}}$ and Korabu Tulasi Balaram Padal ${ }^{2}$ \\ Research Scholar, Department of Mechanical Engineering, Andhra University College of Engineering, \\ Andhra University, Visakhapatnam, Andhrapradesh-530003, India ${ }^{1}$ \\ Professor, Department of Mechanical Engineering, Andhra University College of Engineering, Andhra University, \\ Visakhapatnam, Andhrapradesh-530003, India ${ }^{2}$
}

Received: 07-September-2021; Revised: 17-January-2022; Accepted: 19-January-2022

(C2022 Rapeta Sundara Ramamand Korabu Tulasi Balaram Padal. This is an open access article distributed under the Creative Commons Attribution (CC BY) License, which permits unrestricted use, distribution, and reproduction in any medium, provided the original work is properly cited.

\begin{abstract}
Natural fiber-reinforced composites (NFRC) have elicited great attention from investigators because of their numerous advantages: lightweight, economical production, abundant availability in nature, biodegradability, and consequential environmental safety. Composites with natural fiber-reinforcement consist of reinforcing material and a matrix. The former has a higher density, whereas the latter has ductility and toughness, so that the composite combines both qualities. In this context, it is intuitively logical to investigate the mechanical properties of natural fibers. For this research, it has been the objective to analyze the effect of fiber orientation on the characteristics of flax, hemp, and kenaf. The composite specimens were fabricated through the combination of the hand layup process and cold compression. The tensile test, hardness test, and impact test have been carried out as per American society for testing materials (ASTM) standards for fiber orientations of $0^{\circ}, 15^{\circ}, 30^{\circ}$, and $45^{\circ}$. It has been found that fiber orientation $\left(0^{\circ}\right)$ shows maximum tensile strength for all three composites. The results of experiments indicate that the orientation of fiber influences the characteristics of all three composites. It is worth noting that at 450 fiber orientation, flax shows the least elongation at break in comparison with the other two composites. Furthermore, for 00 fiber orientation, the flax fiber has the highest hardness value, and in the impact test, the kenaf fiber shows the highest value.
\end{abstract}

\section{Keywords}

Flax, Hemp, Kenaf, Tensile strength, Impact strength, Hardness value.

\section{Introduction}

Recently, Natural fiber-reinforced composites (NFRC) have received a lot of attention due to their lightweight, low cost, biodegradability, and environmental friendliness. Natural fibers with precise mechanical and physical qualities are used to create high- performance composites that are both environmentally and cost-effective. When compared to synthetic fiber reinforced composites (SFRC), NFRC has benefits such as reduced solidity, lower cost, and low density, making them suitable for lucrative applications such as the automobile sector, construction, and buildings [1,2].

Fibro granular composites are natural fiber-based composites that have a favorable influence in both indoor and outdoor applications.

*Author for correspondence
It is worth emphasizing that, when compared to basic fiber-based composites, such compounds are less expensive and more successful at dealing with environmental challenges [3, 4]. The disadvantages of NFRC include poor adhesive quality, poor moisture resistance, and poor antifungal properties. For these reasons, synthetic based- composites have gained considerable commercial clout. It should be highlighted that ongoing research is being conducted to enhance the behavior of natural fiber-based treatments by using chemical techniques before manufacturing to eliminate or mitigate the fundamental drawbacks. Some developers have reported on mercerizing and alkali treatment for fiber size reduction, which resulted in measurable improvements in adhesive and anti-fungal characteristics $[5,6]$.The fundamental mechanical characteristics are examined for characterization with the particular goal of using the influence of fiber 
orientation on the relevant behavior of flax, hemp, and kenaf $[7,8]$.

The objective of this paper is to present the efforts made in preparation and testing the mechanical behavior of the NFRC made of flax, hemp, and kenaf. The mechanical properties such as tensile strength, hardness and impact strength of flax, hemp and kenaf fiber reinforced epoxy composites were measured. The extensive literature on the characterization of various NFRC was discussed in section 2. The materials and methods employed for preparing and testing the NFRC specimens made of flax, hemp, and kenaf were presented in section 3. Whereas section 4 covers the test results of tensile behavior, hardness, and impact strength of the specimens prepared with various fiber orientations. The effect of fiber orientation on the mechanical properties of NFRC was discussed in detail in section 5.

\section{Literature review}

The storage modulus and loss tangent, as well as other mechanical parameters, will be affected by changes in fiber orientation. The reason for this is that increasing fiber orientation alters the region of contact between the resin and the reinforcing fibers [9]. Zalacca midrib fiber high-density polyethylene (HDPE) composites with various fiber orientations showed the improved impact and tensile strength, with the 00 fiber orientation giving the best value and the 900 fiber orientations offering the worst [10]. Tensile strength has been increased in composites utilizing kenaf fiber [11]. Natural fiber-reinforced plant structures are commonly found all across nature. They are lightweight and have excellent mechanical qualities. Plant fiber orientation may adjust to a variety of pressures, including windinduced bending [12]. Tensile strength was greater in the longitudinal fiber epoxy vetiver fiber composites than in the transverse and bidirectional fiber epoxy composites. Using vetriver fiber epoxy composites with longitudinal fibers, they have a flexural strength that is $62 \%$ greater than those with transverse fibers and $44 \%$ greater than those with bi-directional fibers [13]. Chemical treatment techniques for kenaf fiber were investigated, as well as their impact on the surface of the fiber and the mechanical characteristics of composites [14]. Mechanical experiments (thickness tests, tensile strength tests, and impact strength tests) and scanning electron microscope (SEM) studies revealed flax fibers to be an alternative natural fiber source for creating reinforced composites with numerous industrial uses [15]. A larger proportion of carbon fabric twill enables the hybrid composite material to have stronger tensile, flexural, and impact strength. Low carbon fabric percentages and high epoxy resin percentages result in lower tensile, flexural, and impact strength, while high carbon fabric percentages and low epoxy resin percentages result in higher tensile, flexural, and impact strength [16]. Experimental findings suggest that increasing fiber length boosts tensile, flexural, and impact strength [17]. Kenaf fiber reinforced epoxy composite has been shown to have increasing mechanical properties with increasing fiber content in terms of flexural strength, impact strength, tensile strength, and hardness. In various sectors such as automotives, furniture, and packaging, kenaf fiber reinforced epoxy composites with 35\% fiber content can replace synthetics with an eco-friendly solution [18]. The experimental results reveal that chemically processed hemp and epoxy composite components will be a more appealing option than man-made or synthetic fiber composite components in car and construction applications [19]. Chemical treatments of natural fibers increase adhesion between the fibers and the matrix, as well as the mechanical properties of composite materials. Natural fiber will soon become one of the sustainable and renewable resources in the composite field and can be used to replace synthetic fibers in many applications [20]. Experimental results indicate that the untreated hemp and glass fiber composites are extremely strong under both tension and flexure [21]. Composite materials may have their mechanical characteristics predicted using the finite element approach. The stress distribution in the composite specimen under tensile and flexural loading conditions was investigated to establish the ideal angle of fiber orientation with the least amount of equivalent stress-induced stress [22]. The focus of this research is to look at the use of flax, hemp, and kenaf fibers as reinforcing elements in an epoxy resin matrix. The use of flax, hemp, and kenaf fibers as reinforcement in the epoxy LY-556 resin matrix has not been submitted to rigorous comparative investigation. This research also investigates the compatibility of flax, hemp, and kenaf fibers as potential reinforcement in epoxy resin, as well as the effect of fiber orientation on the mechanical properties of composites.

\section{Materials and methods}

Unidirectional flax, hemp, and kenaf mats (300 GSM) and Epoxy LY556 with hardener HY951 were obtained from Go Greens Ltd. in Chennai, India. The hand layup method was used to prepare the specimens. Initially, the epoxy and hardener were 
combined in a 10:1 ratio by measuring the proper components. The weight of individual fibers was first determined using a weighing scale. In a 3:1 ratio, epoxy is used. In a 1:10 ratio, the hardener is combined with the epoxy. A stirrer was used to thoroughly combine the resin and hardener. On the relevant fiber material, one layer of the epoxy hardener mix is applied. The epoxy-hardener mixture was then sprayed between the layers. With the aid of rollers, the extra resin is squeezed from the layers. Between the layers, an equal quantity of the resinhardener combination was used. Compression molding was used to cure the material for 24 hours at room temperature under $0.1 \mathrm{MPa}$ pressure. After curing, laminate cutting was performed to obtain American society for testing materials (ASTM) standard specimen sizes at various fiber orientations, namely $0^{\circ}, 15^{\circ}, 30^{\circ}$, and $45^{\circ}$. Tensile, impact, and hardness tests were performed on test specimens. The tests were performed on a batch of three samples for each specimen to ensure reproducibility.

\subsection{Experimental tests}

\subsubsection{Tensile test}

For the tensile test, ASTM D3039 standard specimens were utilized. Test specimens were manufactured to perform the tensile test. The tensile

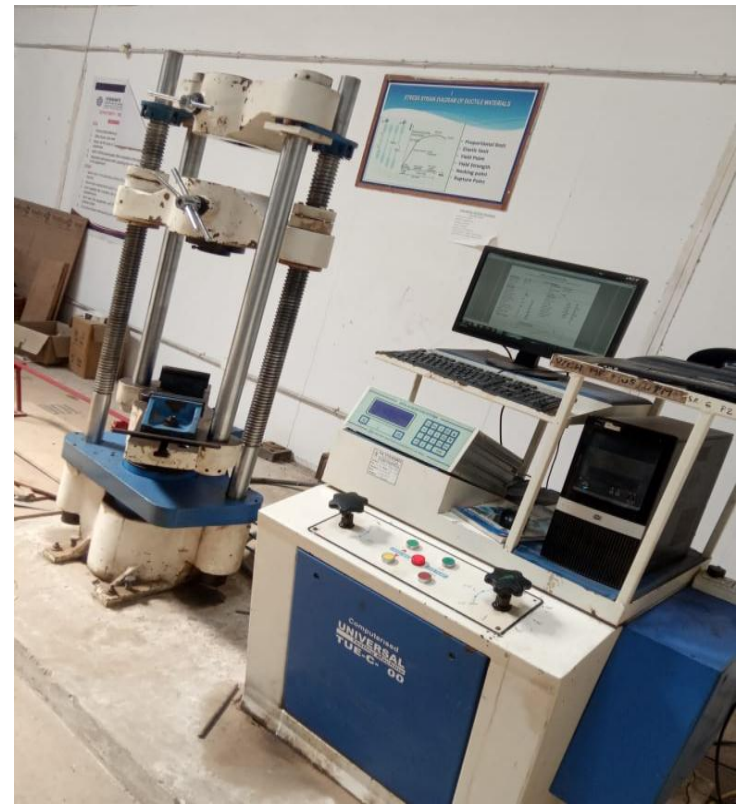

Figure1 Tensile testing apparatus

\subsubsection{Hardness test}

It is used to assess the hardness of a composite in line with ASTM standards. The specimen is indented by using a hardened steel ball. When the maximum load test entails mounting the sample with a clamp and allowing it to be put under tension. The process places the test samples in the setup and increases tension till the fracture occurs. The test was conducted on each sample, and the outcome was examined. The tensile properties of the specimens were measured by using the universal testing machine shown in Figure 1.

The given formula (Equation 1), where $\mathrm{Fn}$ is the force and $\mathrm{A}$ is the cross-section of the gauge section, and $\sigma$ is called engineering stress, can be used to estimate the tensile strength.

$\sigma=\frac{F \mathrm{n}}{A}$

The elongation is calculated against the applied force when tension is applied. The engineering strain $(\varepsilon)$ is determined by using the given formula (Equation 2).

$\varepsilon=\frac{\Delta \mathrm{L}}{\mathrm{Lo}}$

Where Lo is the starting gauge length and $\Delta \mathrm{L}$ is the change in gauge length. The tensile testing apparatus and tensile testing specimens are shown in Figure 1 and Figure 2 respectively.

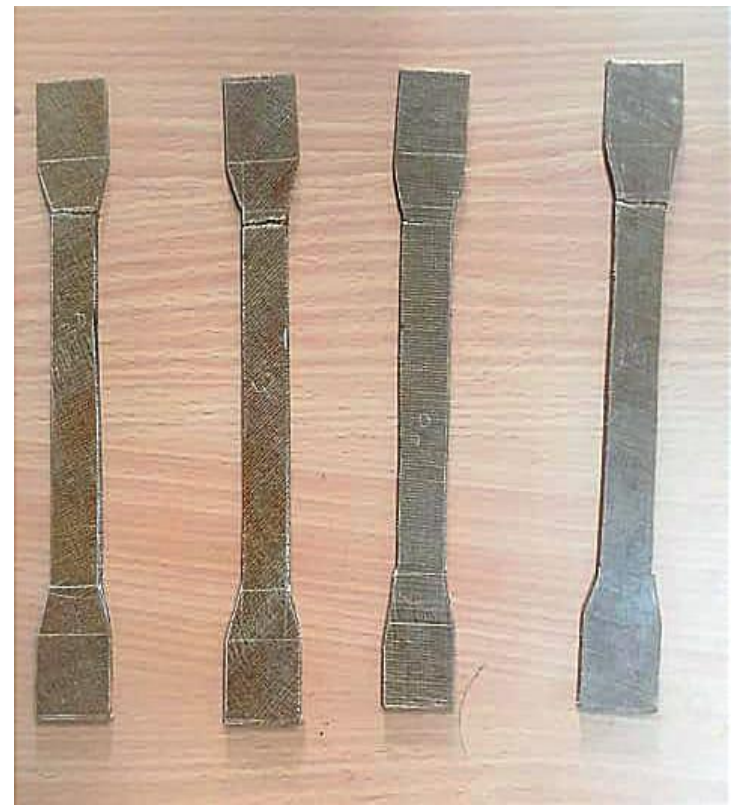

Figure 2 Tensile testing specimens

and equilibrium position are reached to determine the hardness of a material, the external load is removed. The hardness testing apparatus and specimens are shown in Figure 3 and Figure 4 respectively. 


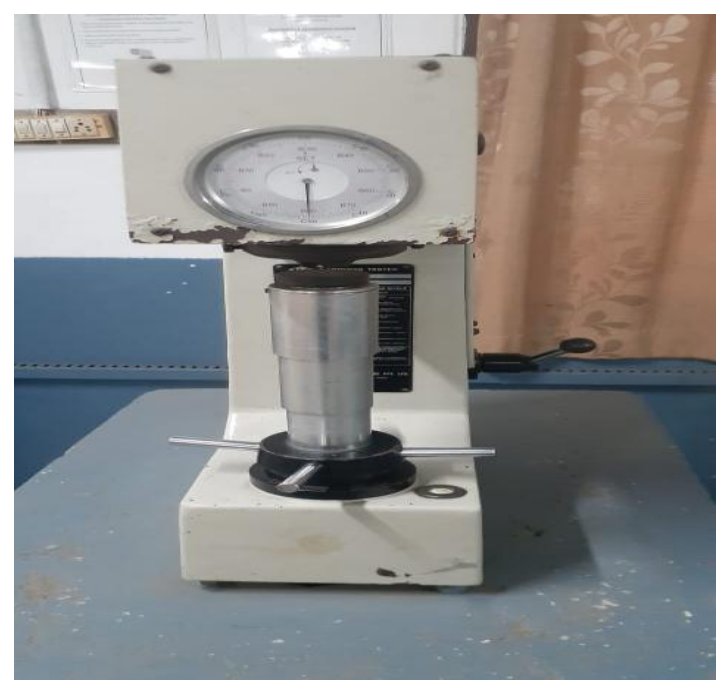

Figure 3 Hardness testing apparatus

\subsubsection{Impact test}

This is a measure of the material's dissipated energy before failure under shock loading conditions. The toughness and yield strength of the material are also measured. It is also feasible to assess the influence of strain rate on the ductility and fracture of the material

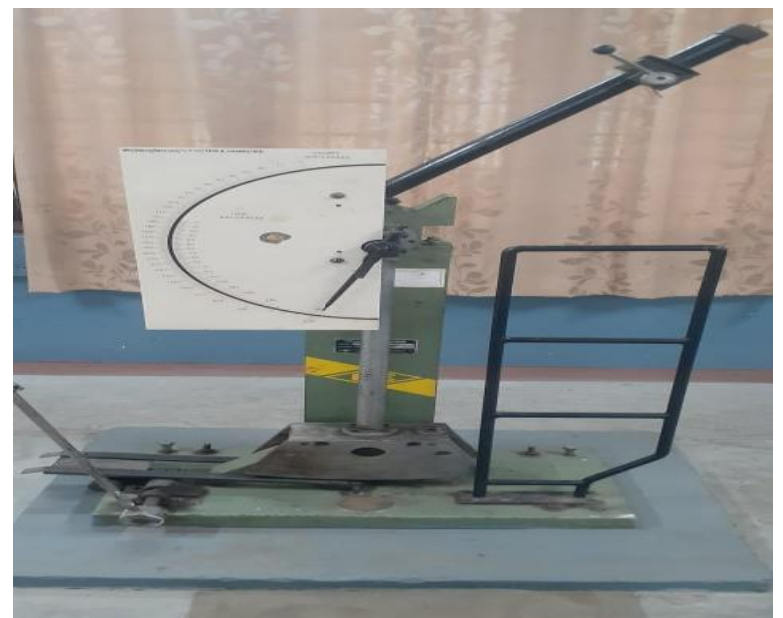

Figure 5 Impact testing apparatus

\section{Results}

The results of the tests are shown in this section. Figure 7 shows the results of the tensile test for various orientations of flax, hemp, and kenaf fiberreinforced composites for comparison. In this work, the testing strength of each fiber orientation was assessed in three different trials. Flax, hemp, and kenaf fiber-reinforced polymers have varied strengths based on their fiber orientation. When compared to other fiber orientations, the 00 fiber orientation gives

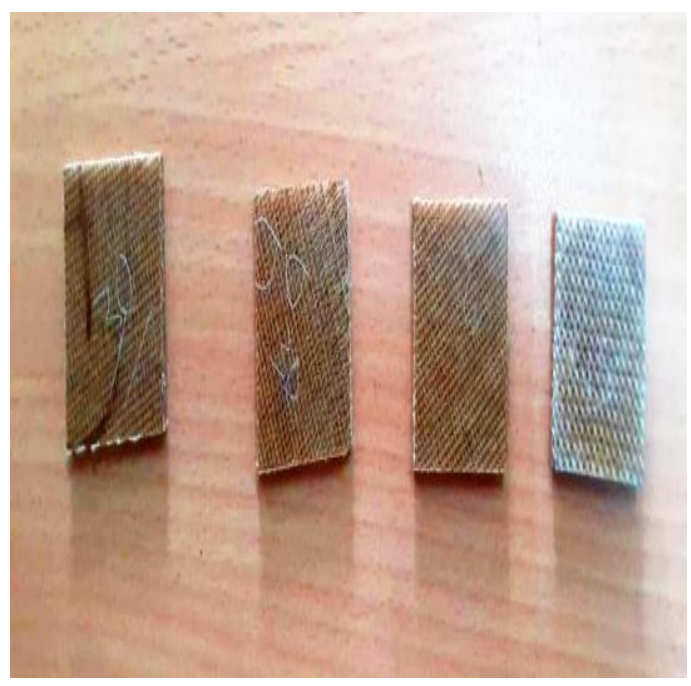

Figure 4 Hardness testing specimens

by performing an impact test. The impact test samples were cut from the individual composites following the ASTM D 256 standard and tested on the impact testing equipment. Figure 5 and Figure 6 show the impact testing device and specimens.

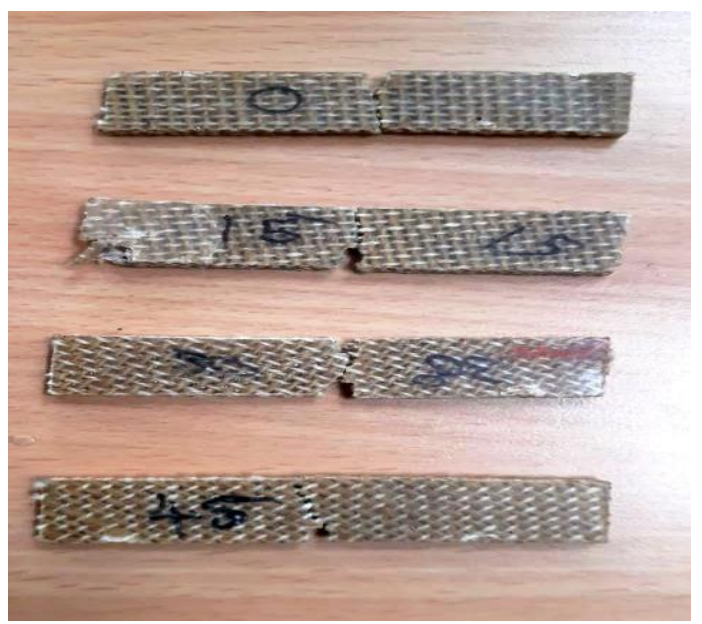

Figure 6 Impact testing specimens

higher tensile strength in fiber composites. As seen in Figure 7, flax, hemp, and kenaf fiber composites all display the same pattern of orientation from 00 to 450 degrees. Stress-strain curves for flax, hemp, and kenaf fiber composites at 00 fiber orientation are as shown in Figure 8, Figure 9 and Figure 10, respectively. Table 1, Table 2 and Table 3 show the influence of varying fiber angles on the tensile strength and percentage of elongation of flax, hemp, and kenaf fiber composites. 
Rapeta Sundara Ramamand Korabu Tulasi Balaram Padal
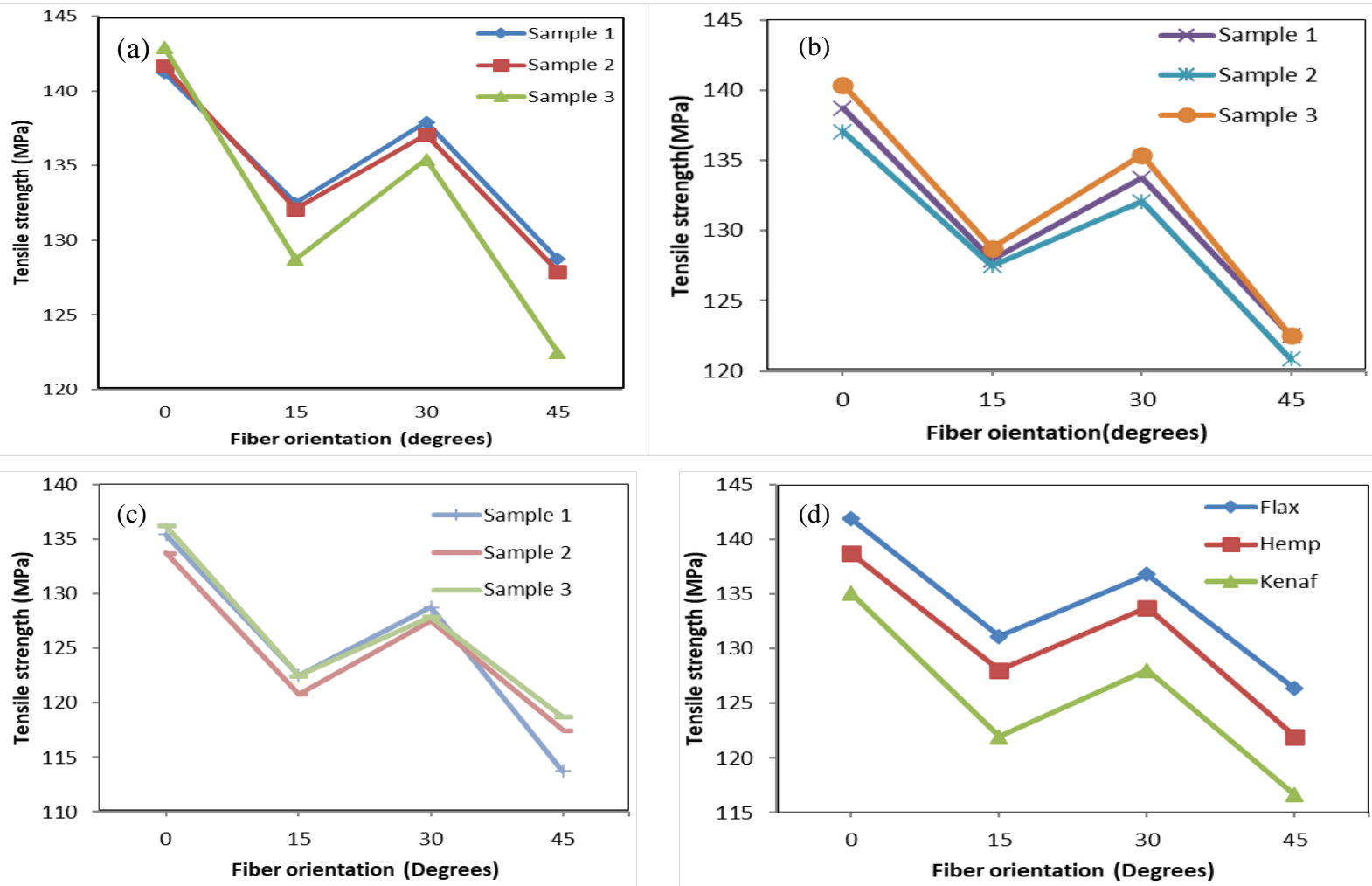

Figure 7 Tensile strength values of (a) flax composite (b) hemp composite (c) kenaf composite (d) all three materials.

Table 1 Tensile strength and elongation values of Flax fiber composite

\begin{tabular}{lll}
\hline Fiber orientation (Degrees) & Tensile strength $(\mathbf{M P a})$ & Elongation at break $(\mathbf{m m})$ \\
\hline 0 & 142.91 & 7.02 \\
\hline 15 & 132.50 & 3.18 \\
\hline 30 & 137.91 & 3.65 \\
\hline 45 & 128.75 & 1.74 \\
\hline
\end{tabular}

Table 2 Tensile strength and elongation values of Hemp fiber composite

\begin{tabular}{lll}
\hline Fiber orientation (Degrees) & Tensile strength $(\mathbf{M P a})$ & Elongation at break $(\mathbf{m m})$ \\
\hline 0 & 140.41 & 3.65 \\
\hline 15 & 128.75 & 2.80 \\
\hline 30 & 135.41 & 3.03 \\
\hline 45 & 122.50 & 2.27 \\
\hline
\end{tabular}

Table 3 Tensile strength and elongation values of Kenaf fiber composite

\begin{tabular}{lll}
\hline Fiber orientation (Degrees) & Tensile strength(MPa) & Elongation at break $(\mathbf{m m})$ \\
\hline 0 & 136.25 & 4.44 \\
\hline 15 & 122.50 & 2.48 \\
\hline 30 & 128.75 & 3.03 \\
\hline 45 & 118.75 & 2.28 \\
\hline
\end{tabular}




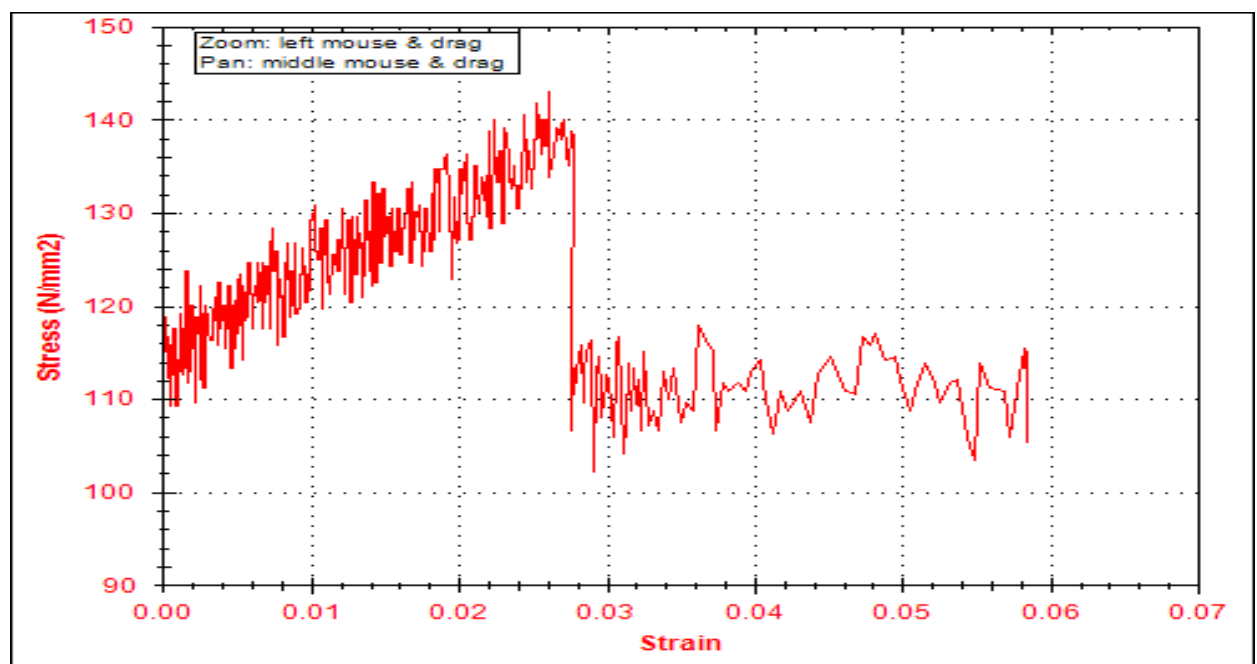

Figure 8 Stress-strain curve for Flax composite

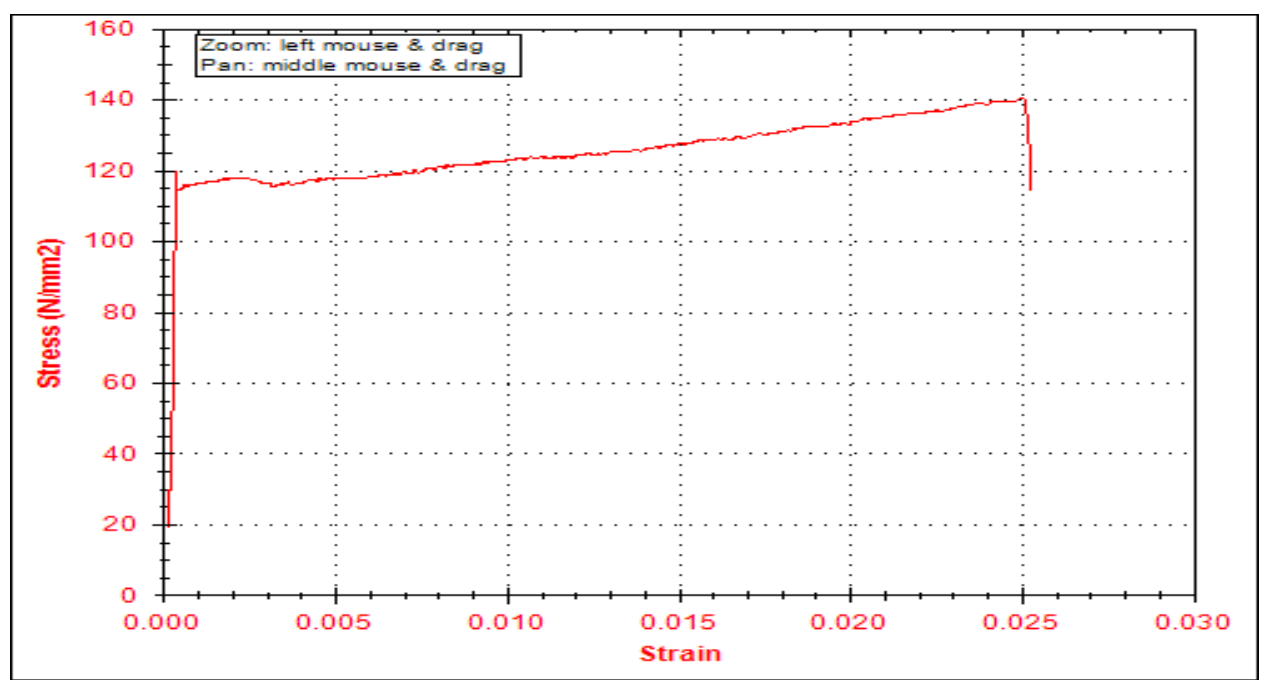

Figure 9 Stress-strain curve for Hemp composite

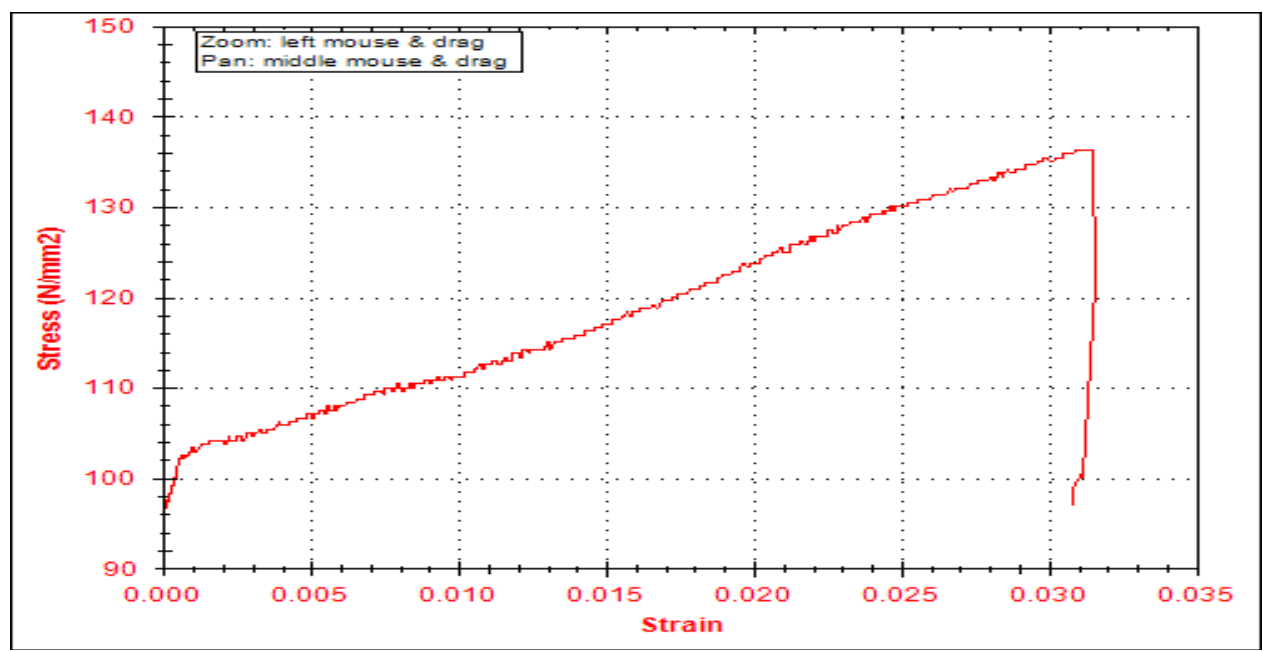

Figure 10 Stress-strain curve for Kenaf fiber composite at 00 fiber orientation 
Figure 11 shows the hardness test results for different orientations of flax, hemp, and kenaf fiber-reinforced composites. The hardness values of each fiber orientation were assessed in three different trials. Figure 12 displays the impact test results for flax,
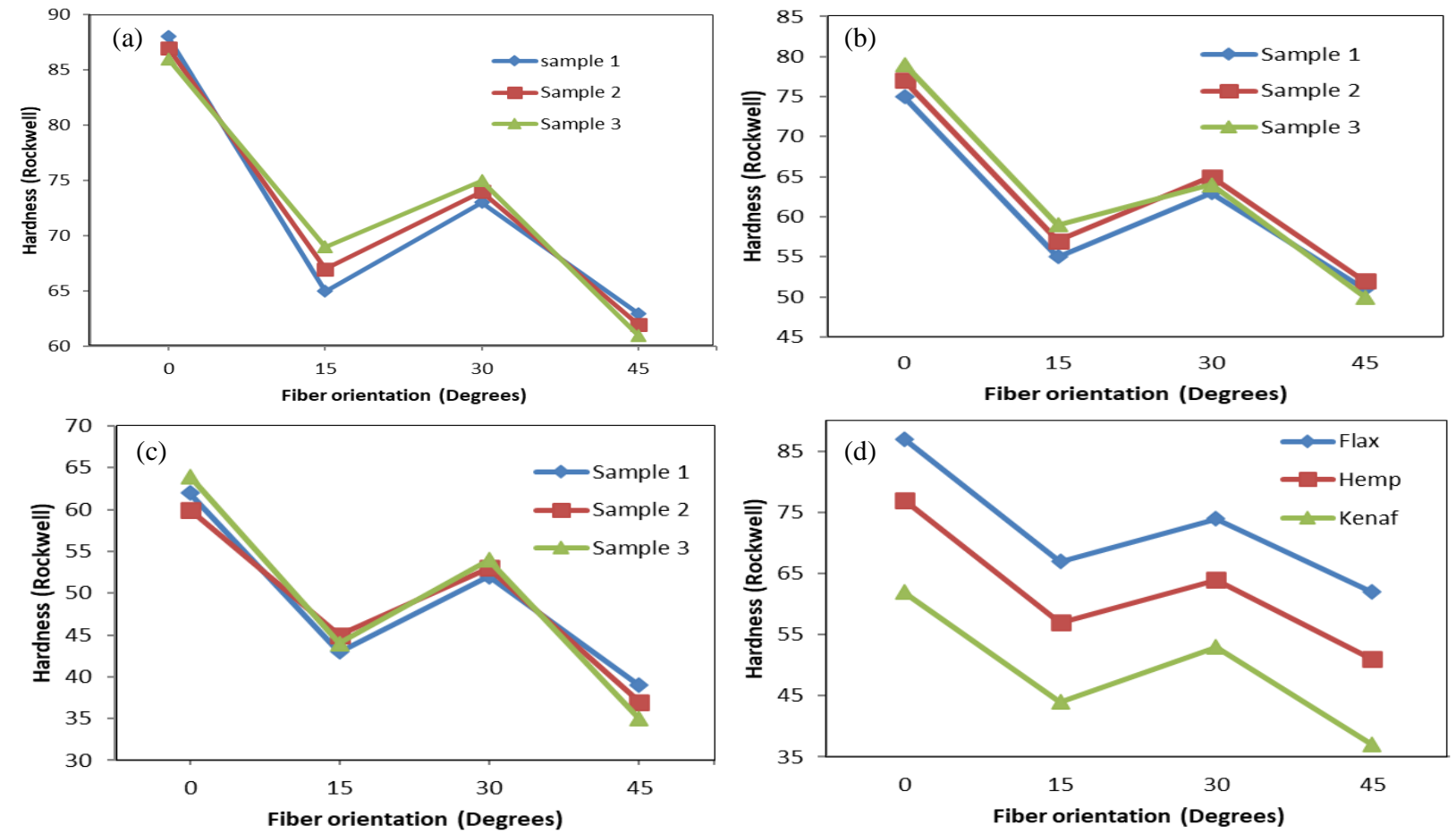

Figure 11 Rockwell hardness number (RHN) of (a) flax composite (b) hemp composite (c) kenaf composite (d) all three materials
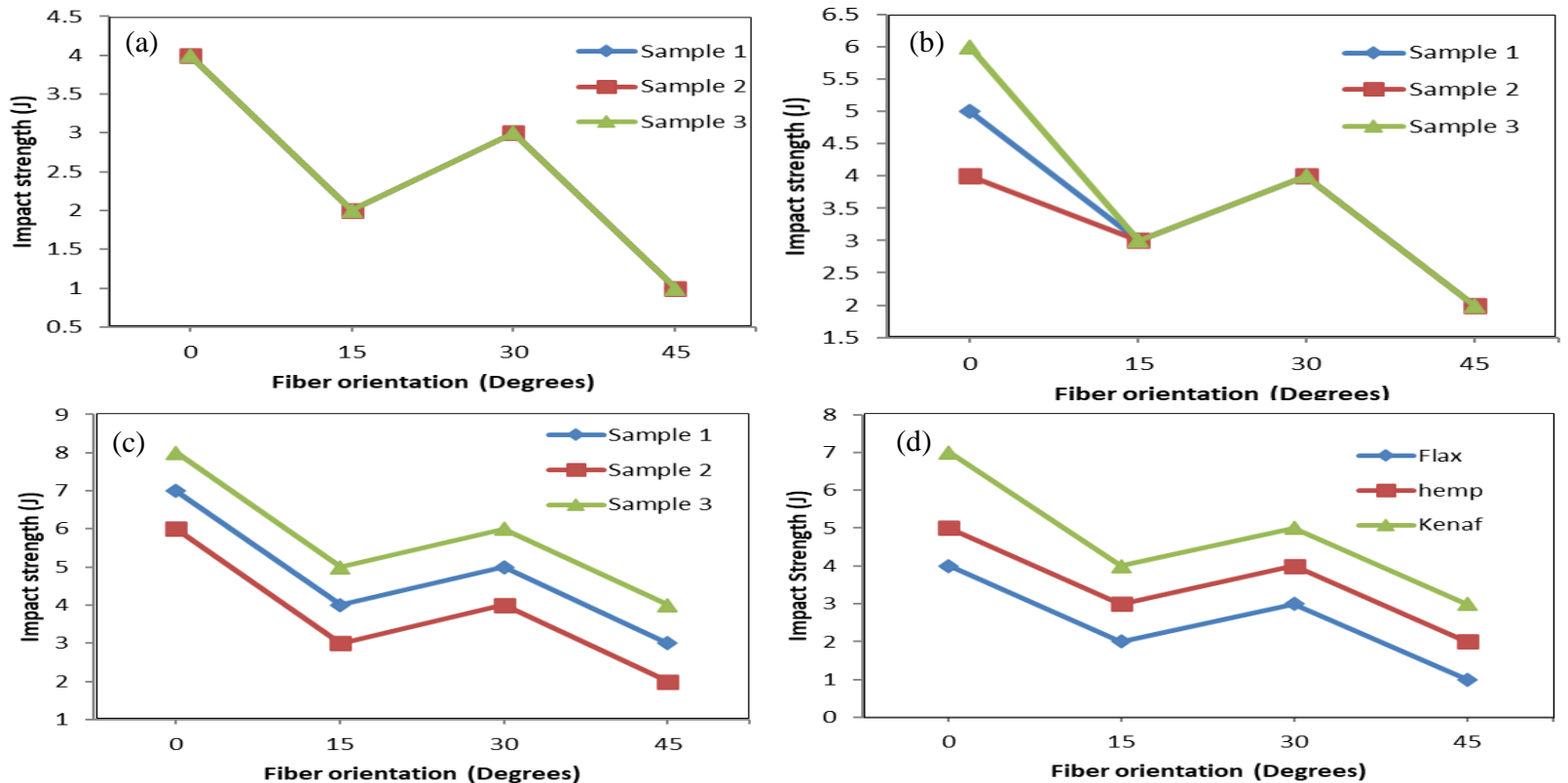

Figure 12 Impact strength values of (a) flax composite (b) hemp composite (c) kenaf composite (d) all three materials 


\section{Discussion}

From the experimental results, it is observed that the fiber orientation influences the mechanical properties such as tensile, hardness, and impact strength. Figure 7 shows a comparison of the tensile strengths of the three composites in orientations of $00,150,300$, and 450. The highest tensile strength values of flax, hemp, and kenaf epoxy-reinforced composites were $142.91 \mathrm{MPa}, 140.41 \mathrm{MPa}$, and $136.25 \mathrm{MPa}$, respectively, at fiber orientation 00 . When compared to other fiber orientations, the tensile strength of allfiber composites is superior for the 00 fiber orientation. As compared to both other composites, the flax composite has less elongation at break for $45^{\circ}$ of fiber orientation. This is because when fibers are oriented at 00 , they are parallel to the applied load, which is evenly distributed across all fibers and transmitted along the fiber axis. In the remaining fiber orientations, however, the fiber axis is not parallel to the load axis. When a tensile load is applied to a specimen with an orientation other than 00, the specimens are subjected to in-plane shear and tensile stresses. The connection of in-plane, shear, and tension causes' off-axis fiber pulling, producing specimen failure before ultimate strength is reached. Figure 11 show that fiber orientation 00 has the greatest hardness value across all three composites. The fiber orientation 00 for flax fiber shows the highest hardness value of RHN88 among the other two fiber composites. The hardness values of flax, hemp, and kenaf fiber-reinforced epoxy composites demonstrate that the curves for all three fiber composites follow the same pattern from 00 to 450 orientations. As shown in Figure 12, the best impact strength is found in orientation 00 for all three composites. When the fiber orientation is 00 , all three fiber composites have the most impact energy, and when it is 450, they have the lowest. The fiber composite prepared with fiber orientation 00 for kenaf fiber, which is the strongest of the three tested, has impact strength of 8 joules. As seen in Figure 12, the impact strength values of all three composites are quite close to each other. This is due to the epoxy resins' capability to develop a strong bond between matrix and fiber even in the absence of a binding agent. The Charpy impact energy characteristics of flax, hemp, and kenaf fiber reinforced epoxy composites are compared, and the curves follow the same pattern from 00 to 450 orientation. The massto-volume ratio in composites is unaffected by fiber orientation, regardless of the orientation of the fibers.
The applied load is distributed linearly over all plies and fiber orientations in composites with 00 fiber orientation, resulting in a greater strain value at failure. As a consequence, mechanical interlocking between layers may be more effective, and stress distribution within a matrix and its fibers is usually good enough to reach higher testing strengths. Other composites have lower testing strength ratings when the applied force is perpendicular to the direction of the fibers. The limitation of this work is that one of the applications for these composites is brake pads, and in that application there could be a chance of incorporating ceramic hard particles to get high wear resistance. But in our work, we cannot use the highdensity particles since they will segregate at the bottom, reducing the strength of the composites. A complete list of abbreviations is shown in Appendix I.

\section{Conclusion and future work}

This paper presents the efforts made in the preparation and experimental characterization of NFRC. The mechanical characteristics of NFRC are evaluated by measuring the tensile strength, hardness value, and impact strength using the universal testing machine, Rockwell hardness testing machine, and Charpy impact testing equipment. Tensile tests were performed to determine the tensile strength of all three fiber-reinforced composites at a maximum load of $400 \mathrm{KN}$. From the experimental results, it is observed that the flax fiber-reinforced composites with 00 fiber orientations show the highest tensile strength value of $142.91 \mathrm{MPa}$ among the three natural fiber composites such as flax, hemp, and kenaf, and it is found that the tensile strength values are affected by changing the fiber orientation. According to the experimental findings, the flax fiber-epoxy reinforced composite with 00 fiber orientation gives the maximum hardness rating of RHN88 and ranges from RHN61 to RHN88 among the other two fiber composites. The greatest value of impact strength is found for kenaf material among the other two at 00 fiber orientation, at 8 joules. It is worth noting that all three natural fiber composites discussed in this study had the greatest values for tensile strength, hardness, and impact strength at fiber orientation of 00 . The usage of various natural and synthetic fibers with various resins and hardeners may be considered as a future scope of work for different applications.

\section{Acknowledgment}

None. 
Conflicts of interest

The authors have no conflicts of interest to declare.

\section{Authors contribution statement}

Rapeta Sundara Ramam: Conceptualization, investigation, data collection, analysis and interpretation of results, writing, review and editing. Korabu Tulasi Balaram Padal: Conceptualization, supervision, investigation on challenges and draft manuscript preparation, writing, review and editing.

\section{References}

[1] Sen T, Reddy HJ. Various industrial applications of hemp, kinaf, flax and ramie natural fibres. International Journal of Innovation, Management and Technology. 2011; 2(3):192-8.

[2] Mohammed L, Ansari MN, Pua G, Jawaid M, Islam MS. A review on natural fiber reinforced polymer composite and its applications. International Journal of Polymer Science. 2015.

[3] Kumbhar T, Chavand DS, Shendokar DS. A review on natural composites. IOSR Journal of Mechanical and Civil Engineering. 2018:88-95.

[4] Ahmad F, Choi HS, Park MK. A review: natural fiber composites selection in view of mechanical, light weight, and economic properties. Macromolecular Materials and Engineering. 2015; 300(1):10-24.

[5] Bachchan AA, Das PP, Chaudhary V. Effect of moisture absorption on the properties of natural fiber reinforced polymer composites: a review. Materials Today: Proceedings. 2021; 49(8):3403-8.

[6] Sahu P, Gupta MK. A review on the properties of natural fibres and its bio-composites: effect of alkali treatment. Proceedings of the Institution of Mechanical Engineers, Part L: Journal of Materials: Design and Applications. 2020; 234(1):198-217.

[7] Pickering KL, Efendy MA, Le TM. A review of recent developments in natural fibre composites and their mechanical performance. Composites Part A: Applied Science and Manufacturing. 2016; 83:98-112.

[8] Sathish S, Kumaresan K, Prabhu L, Gokulkumar S, Dinesh S, Karthi N. Experimental testing on mechanical properties of various natural fibers reinforced epoxy hybrid composites. Indian Journal of Science and Technology. 2018; 11(25):1-6.

[9] Doddi PR, Chanamala R, Dora SP. Effect of fiber orientation on dynamic mechanical properties of PALF hybridized with basalt reinforced epoxy composites. Materials Research Express. 2020; 7(1):112

[10] Lasikun, Ariawan D, Surojo E, Triyono J. Effect of fiber orientation on tensile and impact properties of zalacca midrib fiber-HDPE composites by compression molding. In AIP conference proceedings 2018 (pp.1-5). AIP Publishing LLC.

[11] Vinoth KS, Ansari MN, Begum S, Yahya Z, Atiqah A. Effect of fibre loading on tensile strength of kenaf/glass fibre epoxy hybrid composite for insulator application. Materials Today: Proceedings. 2020; 29:123-6.
[12] Cordin M, Bechtold T, Pham T. Effect of fibre orientation on the mechanical properties of polypropylene-lyocell composites. Cellulose. 2018; 25(12):7197-210.

[13] Natarajan S, Thamba NB, Nandi S, Kavitha KV, Ayyagari S. Effect of fiber orientation on the tensile and flexural properties of vetiverfiber reinforced epoxy composites. In IOP conference series: materials science and engineering 2021 (pp. 1-7). IOP Publishing.

[14] Ibrahim NA, Hadithon KA, Abdan K. Effect of fiber treatment on mechanical properties of KENAF fiberecoflex composites. Journal of Reinforced Plastics and Composites. 2010; 29(14):2192-8.

[15] Kumar A, Ramratan, Kumar R. Experimental investigation of mechanical and physical properties of short flax fibres pulp reinforced composite material sheet. Modern Approaches in Material Science. 2020; 2(5):304-12.

[16] Ramesh A, Rao MG, Maneiah D, Raji RA. Experimental investigation on the mechanical properties of flax, E-glass and carbon fabric reinforced hybrid epoxy resin composites. In AIP conference proceedings 2019.

[17] Palanikumar K, Ramesh M, Hemachandra RK Experimental investigation on the mechanical properties of green hybrid sisal and glass fiber reinforced polymer composites. Journal of Natural Fibers. 2016; 13(3):321-31.

[18] Rajamanickam SK, Ravichandran V, Sattanathan S, Ganapathy D, Dhanraj JA. Experimental investigation on mechanical properties and vibration damping frequency factor of kenaf fiber reinforced epoxy composite. SAE Technical Paper. 2019:1-6.

[19] Bhoopathi R, Ramesh M. Mechanical properties' evaluation of hemp fibre-reinforced polymer composites. In advances in materials and metallurgy 2019 (pp. 343-51). Springer, Singapore.

[20] Thyavihalli GYG, Mavinkere RS, Parameswaranpillai J, Siengchin S. Natural fibers as sustainable and renewable resource for development of eco-friendly composites: a comprehensive review. Frontiers in Materials. 2019.

[21] Bhoopathi R, Ramesh M, Kumar MN, Balaji PS, Sasikala G. Studies on mechanical strengths of hempglass fibre reinforced epoxy composites. In IOP conference series: materials science and engineering 2018 (pp. 1-8). IOP Publishing.

[22] Gupta US, Dharkar A, Dhamarikar M, Choudhary A, Wasnik D, Chouhan P, et al. Study on the effects of fiber orientation on the mechanical properties of natural fiber reinforced epoxy composite by finite element method. Materials Today: Proceedings. 2021; 45:7885-93. 


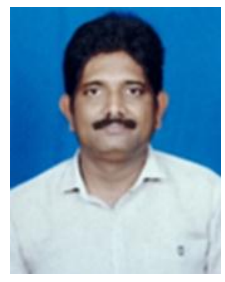

Rapeta Sundara Ramam works as an Associate Professor at Vignans Institute of Information Technology in Visakhapatnam and is a part-time research scholar at Andhra University. He received his undergraduate degree from Nagarjuna University and his postgraduate degree from JNTUK,

Kakinada. He has been a teacher for almost 20 years. Composite Materials are one of his research interests.

Email: sundar.ramam@gmail.com

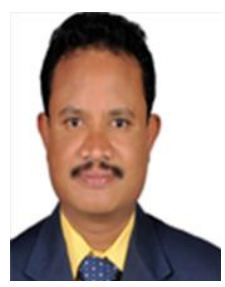

Korabu Tulasi Balaram Padal is a professor at Andhra University in Visakhapatnam, Andhra Pradesh, India. Andhra University has awarded him a doctorate in philosophy. He's been a teacher for more than two decades. He has authored over ten research articles that have been published in prestigious national and international publications. Composite Materials are one of his areas of study.

Email: ktbpadaldme@gmail.com

\begin{tabular}{lll}
\multicolumn{2}{l}{ Appendix I } \\
\hline S. No. & Abbreviation & Description \\
\hline 1 & ASTM & $\begin{array}{l}\text { American Society for Testing } \\
\text { Materials }\end{array}$ \\
\hline 2 & GSM & Grams per square meter \\
\hline 3 & HDPE & High-Density Polyethylene \\
\hline 4 & MPa & Megapascal \\
\hline 5 & NFRC & $\begin{array}{l}\text { Natural } \\
\text { Composite }\end{array}$ \\
\hline 6 & RHN & Rockwell Hardness Number \\
\hline 7 & SEM & Scanning Electron Microscope \\
\hline 8 & SFRC & $\begin{array}{l}\text { Synthetic } \\
\text { Composite }\end{array}$ \\
\hline & & Fiber-Reinforced \\
\hline
\end{tabular}

